\title{
To Battle COVID-19's Twin Economic and Health Crises, Medicaid Needs Flexible Funding Structures for Stabilization
}

\author{
Patrick N. O'Mahen, $\mathrm{PhD}^{1,2}$ (1) and Laura A. Petersen, MD MPH', \\ 'The Center for Innovations in Quality, Effectiveness and Safety (IQuESt), Michael E. DeBakey VA Medical Center, Houston, TX, USA; ${ }^{2}$ Section of Health \\ Services Research, Department of Medicine, Baylor College of Medicine, Houston, TX, USA.
}

Medicaid, which provides health insurance to low-income Americans, is a joint federal-state partnership that manifests as 50 unique state programs. States have policy flexibility to design programs within federal parameters. However, Medicaid also requires funding flexibility to encourage states to maintain services during times of crisis when more people need Medicaid. Currently, Medicaid's funding formula, the Federal Medical Assistance Percentage (FMAP), adjusts federal spending by state levels of economic development but fails to adjust for nationwide recessions. During economic contractions, the federal government should use its ability to run budget deficits to reimburse states at higher rates in exchange for maintaining services. In turn, during economic expansions, states should shoulder relatively more costs of Medicaid. Although the current FMAP boost provided under the Families First Coronavirus Response Act has reduced strain on state Medicaid programs, it does not account for the severity of state-specific downturns and is limited to the current emergency. Instead of ad hoc, across-theboard FMAP boosts to respond to each crisis, Congress should pass legislation making automatic adjustments based on changes in state unemployment rates.

J Gen Intern Med 36(4):1067-70

DOI: $10.1007 / \mathrm{s} 11606-020-06457-y$

(c) This is a U.S. government work and not under copyright protection in the

U.S.; foreign copyright protection may apply 2021

$\mathrm{T}$ he COVID-19 pandemic has exposed serious weaknesses in the American policy response to economic and health emergencies. One critical need is to reinforce Medicaid, which provides health insurance to poor and vulnerable Americans, so it can weather acute financial, enrollment, and health care burdens in the face of catastrophic events such as pandemics.

\section{TWO TYPES OF FLEXIBILITY IN MEDICAID}

Medicaid, which covered 64 million Americans in lowincome households in February $2020,{ }^{1}$ is a partnership

Received July 28, 2020

Accepted December 13, 2020

Published online January 22, 2021 between federal government and states. That partnership is marked by shared responsibility for policy design and funding. As a result, the program takes a unique form in each state. This shared responsibility also incorporates two distinct types of flexibility: policy flexibility, and funding flexibility.

Policy flexibility allows each state to design its own unique Medicaid program within broad parameters set by the federal government. States must cover certain core populations and mandated services but have wide latitude to offer optional services or extend coverage to optional populations. For example, states have the option of offering dental or optometry services to adults. $^{2}$ States also have the ability to determine how they structure coverage of groups and services, using a wide variety of structures ranging from fee-for-service through multiple flavors of managed care. ${ }^{3}$ The Affordable Care Act's Medicaid expansion, which covers all parents and childless adults up to $138 \%$ of the poverty line, is another example of an optional program that states have made different choices on accepting. ${ }^{4,5}$

Federal waivers allow states additional policy flexibility. Section 1115 of the Social Security Act allows states to negotiate agreements with the federal government that can waive requirements of the Medicaid law in order to create demonstration projects that advance the underlying aim of the program. ${ }^{6}$ Yet, another set of innovation waivers allowed under Section 1332 of the Affordable Care Act permits states to take money designated for ACA Medicaid expansion populations and redeploy it to alternative coverage schemes, assuming the state demonstrates it can cover the same or greater number of people with similar or higher levels of coverage. ${ }^{7}$ States have used both types of waivers to implement managed care, fund auxiliary services, cover additional populations, or experiment with mandating cost-sharing for certain recipients, ${ }^{8,} 9$ though the federal judiciary has thus far blocked waivers that impose work requirements on recipients. ${ }^{10}$

Shared responsibility for policy development is mirrored by the State and federal governments sharing costs. Like policy design, funding arrangements vary by state, providing funding flexibility as well as policy flexibility. The federal government reimburses a portion of total annual expenses, calculated through the Federal Medical Assistance Percentage $(\text { FMAP })^{11}$ calculation ranging between 50 and $83 \%$, depending on a state's relative per-capita income. Median-income states receive 55\% reimbursement, with poorer states gaining proportionately more in matching funds and wealthier states 
getting less. States accepting the ACA's Medicaid expansion receive an FMAP of $90 \%$ for expansion-related groups. As currently set by law then, funding flexibility represents an automatic function of the relative economic development of states, not an active set of choices.

Section 1115 waivers offer a partial exception to this automatic reimbursement. In requesting policy flexibility, states may request increased funding flexibility in the form of redirecting federal funding from statutorily required programs to experimental programs. However, funding flexibility for waivers is limited by the requirement of revenue neutrality, which means that any state policy experiments will not cost the federal government more than the standard policy would. ${ }^{6}$ Furthermore, Section 1115 waivers are conditional on priorities of the current presidential administration.

A federal emergency declaration removes the neutrality requirement, which opens the door to increased federal aid. For example, in 2016, the Obama administration declared a public health emergency in Flint after the city's water supply was contaminated by lead. Within a month, the state and federal government quickly negotiated a waiver expanding Medicaid to pregnant women and anyone under the age of 21 with household income under $400 \%$ of the poverty line, enrolling more than 36,000 new people in the program. The waiver also expanded permissible covered services to include lead abatement. ${ }^{12}$ Emergency declarations also allow the federal government to waive federal and state comment periods and reduce paperwork for enrollees after disasters. After the Sept. 11, 2001, terrorist attacks and Hurricane Katrina in 2005, New York and Louisiana (respectively) quickly requested, and the federal government approved, letting Medicaid enrollees self-attest to eligibility for several months after the disaster so they could more quickly gain access to necessary health services. $^{12}$

Emergencies aside, however, the assumptions of revenue neutrality for waivers, limitations imposed by the presidential administration in power, and the stiffness of the FMAP reimbursement formula all limit funding flexibility. FMAP only adjusts on a 3 -year rolling average, meaning that it is slow to adjust to local and regional economic downturns, ${ }^{13}$ only providing relief well after rising unemployment has left individuals without health care for months or years. More importantly, FMAP assumes a roughly static relationship in overall cost share between the states and federal government, regardless of the overall national economic climate.

\section{VICIOUS CYCLES: HOW HIGHER POLICY FLEXIBILITY WITH LIMITED FUNDING FLEXIBILITY ENCOURAGES CUTS DURING DOWNTURNS}

Limited financial resources place serious constraints on a state's abilities to maximize Medicaid's effectiveness in a crisis. Economic downturns pressure Medicaid programs from multiple sides. Rising unemployment increases the
Medicaid rolls and costs as workers lose both their income and their health insurance that covers their families. ${ }^{14}$ During the 2008-2009 recession, Medicaid spending grew to more than $22 \%$ of state budgets. ${ }^{11}$ At the same time, decreased economic activity shrinks the income, business, and sales tax revenues that fund state budgets. Because Medicaid programs represent a large share of state budgets, optional programs become targets for cuts when Americans are likely most in need of Medicaid. ${ }^{11}, 13,15$ Roughly 20 states deeply cut health care spending, including Medicaid, after the FMAP boost was discontinued in 2011. ${ }^{16}$ These cuts can have impacts on both health coverage and health outcomes. ${ }^{15,17}$

High policy flexibility with low funding flexibility incentivizes states to jettison optional programs or coverage populations during economic downturns, although states still must accept applicants from mandatory coverage groups and for mandatory services. Just as there are good reasons for Medicaid to have high policy flexibility to allow states the ability to develop programs tailored to individualized needs, Medicaid also needs high funding flexibility so it can transition smoothly from routine operations into the expanded capability needed for crisis response. This need is starker during the current economic collapse - caused by the COVID-19 pandemic - in which the very source of the economic crisis is a disease that requires vast health care expenditures to test, track, and treat millions of Americans.

\section{ADVANTAGES OF FEDERAL FUNDING DURING CRISIS}

The federal government has unique advantages over states in providing funding during a crisis. 49 states have balanced budget requirements that sharply limit their ability to fund annual operations through borrowing. ${ }^{13}$ In contrast, the federal government can legally run a deficit and borrow money in its own currency. These abilities give it vast capacity to engage in deficit spending to deploy resources and reinforce critical services during emergencies. To fight the Second World War, for example, in 1943 the US government ran a budget deficit equivalent to an astonishing $29.6 \%$ of gross domestic product with no long-term ill effects on the country's financial health. ${ }^{18}$ Dramatically increasing federal aid to state health programs during COVID-19 both retains health system capacity to treat the pandemic and staves off economic collapse: Keeping health providers solvent and employed keeps medical professionals on the job fighting the outbreak while their paychecks stimulate the economy. ${ }^{13}$

As discussed above, Section 1115 authority remains a useful crisis-response tool for these purposes. But it suffers from several critical shortcomings. First, until now it has only been used for local and regional emergencies, not in a pandemicinduced long-term nationwide economic crisis. Second, because states must contribute their standard share of costs to draw down additional federal funds, it also does little to relieve 
pressure on state finances. Finally, issuing waivers requires discretion and action on the part of the executive branch, which may delay action depending on the capacity and priorities of a given presidential administration.

A more direct and comprehensive method to treat the underlying fiscal weaknesses of Medicaid during economic downturns is for the federal government to temporarily boost state FMAPs during crisis. Increasing federal matching rates for states removes the fiscal burden from an entity that can least handle it (the state) to the entity with the ability to finance it (the federal government). Conditioning this action on states maintaining or expanding their programs preserves Medicaid's effectiveness in a crisis.

Federal FMAP increases have happened three times since 2000, each in response to recessions. The largest was a part of the American Reinvestment and Recovery Act (the Obama Stimulus), which boosted FMAP by 6.2 percentage points from January 2009 through June 2011, while also giving states an additional increase based on their unemployment rates. The action preserved coverage for the increased number of state Medicaid recipients while offering states financial relief: though overall spending on Medicaid increased, state Medicaid expenditures decreased slightly during the recession despite maintenance of effort requirements for states. ${ }^{11}$

Most recently, Congress acted to raise the FMAP for states by 6.2 percentage points in the Families First Coronavirus Response Act passed in March. The increased aid is retroactive to the start of 2020 and will last until the end of the public health emergency. ${ }^{19}$

These FMAP increases, which are conditioned on states maintaining eligibility and service standards, are helpful for preserving state Medicaid programs during hard times. Introducing higher levels of funding flexibility to backstop state programs with federal resources rebalances the incentive structure of high state policy flexibility toward meeting local needs and away from cutting programs during recessions.

However, FMAP reform needs to go further to robustly protect health coverage for low-income Americans. Adjusting FMAP levels uniformly across all states fails to account for particular levels of need generated by the depth, timing, and relative length of downturns across specific regions. This means that the Families First Act falls short of the Obama stimulus, which also included some state-specific adjustments for changes in local unemployment rates. Second, the levels in the Families First Act are likely inadequate because the recession generated by the COVID-19 crisis is more severe than the 2008-2009 Great Recession.

Most fundamentally, requiring an act of Congress to increase FMAP during every crisis is cumbersome, especially at present when asymmetrically polarized political parties make a unified Congressional crisis response more difficult and uncertain. ${ }^{20} \mathrm{~A}$ better method would be to create an automatic stabilizer, under which increases in a state's unemployment rate over certain thresholds would trigger increases in FMAP. Researchers have proposed several versions of this trigger over the years, ${ }^{13,}{ }^{21}$ each of which if adopted would have provided states more resources to fight COVID-19, shield essential public services from counterproductive cuts, and generate essential economic stimulus to counteract the recession. In March 2020, House Democrats introduced a bill, HR 6379, which would automatically implement state-specific FMAP increases of 4.8 percentage points for each increase in unemployment of 1 percentage point over a state-specific preset threshold calculated from a state's historical unemployment rates, capping the federal share of Medicaid expenditures at $95 \% .^{22}$ The proposal is a more generous version of a Brookings' Institution proposal projected to reduce the state burden of economic deterioration on Medicaid programs by two-thirds. ${ }^{13}$

Creating automatic increases to federal matching grants during times of crisis in exchange for maintenance of effort improves Medicaid's funding flexibility. Although ideological preferences for cutting Medicaid services remain in many states, higher levels of funding flexibility remove one major incentive for states to use policy flexibility to cut optional programs. As a result, more Americans retain access to comprehensive health care. Such reforms guarantee that Medicaid's primary purpose, providing health care for vulnerable Americans, will be fulfilled at the precise moment when all citizens need it most.

Acknowledgments: This material is based upon work supported in part by the Department of Veterans Affairs, Veterans Health Administration, Office of Research and Development, and the Center for Innovations in Quality, Effectiveness and Safety (CIN 13-413).

Corresponding Author: Laura A. Petersen, MD MPH; The Center for Innovations in Quality, Effectiveness and Safety (IQuESt), Michael E. DeBakey VA Medical Center, 2002 Holcombe Blvd., Houston, TX 77030 , USA (e-mail: laurap@bcm.edu).

\section{Compliance with Ethical Standards:}

Conflict of Interest: The authors declare that they do not have a conflict of interest.

Disclaimer: The views expressed in this article are those of the authors and do not necessarily represent those of the Veterans Health Administration or the US Government.

\section{REFERENCES}

1. Centers for Medicare and Medicaid Services. January 2020 Medicaid \& CHIP Enrollment Data Highlights. https://www.medicaid.gov/medicaid/ program-information/medicaid-and-chip-enrollment-data/report-highlights/index.html. Published 2020. Accessed May 8, 2020.

2. Centers for Medicare and Medicaid Services. Mandatory and Optional Medicaid Benefits. https://www.medicaid.gov/medicaid/benefits/mandatory-optional-medicaid-benefits/index.html. Accessed June 1, 2020.

3. Hinton E, Rudowitz R, Diaz M, Singer N. Ten Things to Know About Managed Care; 2019. https://www.kff.org/medicaid/issue-brief/10things-to-know-about-medicaid-managed-care/. Accessed July 11, 2020.

4. Garfield R, Damico A, Orgera K. The Coverage Gap: Uninsured Poor Adults in States that Do Not Expand Medicaid. https://www.kff.org/ medicaid/issue-brief/the-coverage-gap-uninsured-poor-adults-instates-that-do-not-expand-medicaid/. Published 2018.

5. O'Mahen P, Petersen L. State-level political institutions matter: the balance of powers among governors, legislatures, and direct democracy influences medicaid expansion decisions. World Med Health Policy. 2020. https://doi.org/10.1002/wmh3.329. 
6. Rose S. Financing medicaid: federalism and the growth of America's health care safety net. Ann Arbor: University of Michigan Press; 2013.

7. Wright B, Porter A, Singer PM, Jones DK. The devolution of health Reform? A comparative analysis of state innovation waiver activity. J Health Polit Policy Law. 2018. https://doi.org/10.1215/036168787277404 .

8. Henry J. Kaiser Family Foundation. Tracking Section 1332 State Innovation Waivers. https://www.kff.org/health-reform/fact-sheet/ tracking-section-1332-state-innovation-waivers/. Published 2020. Accessed June 1, 2020.

9. The Henry J. Kaiser Family Foundation. Medicaid Waiver Tracker: Approved and Pending Section 1115 Waivers by State. https://www.kff. org/report-section/section-1115-waiver-tracker-definitions/. Published 2020. Accessed July 11, 2020.

10. O'Mahen PN, Petersen LA. State governments and judges may moderate the impact of the Trump administration's promotion of Medicaid work requirements. J Gen Intern Med. 2019;34(9):1899-1902. https://doi. org/10.1007/s11606-019-04846-6.

11. Mitchell A, Baumrucker EP. Medicaid: The Federal Medical Assistance Percentage (FMAP); 2012. https://www.everycrsreport.com/files/ 20120127_RL32950_5f3c4dd988ceb3bleeac96f7de099a046e2356da. pdf. Accessed July 11, 2020.

12. Medicaid and CHIP Payment and Access Commission. Medicaid's Role in Disasters and Public Health Emergencies; 2018. https://www.macpac. gov/wp-content/uploads/2018/03/Medicaid's-Role-in-Disasters-and Public-Health-Emergencies.pdf. Accessed July 11, 2020.

13. Fiedler M, Furman J, Powell III W. Increasing Federal Support for State Medicaid and CHIP Programs in Response to Economic Downturns; 2019. https://www.brookings.edu/wp-content/uploads/2019/05/ES_ THP_FFP_web_20190506.pdf. Accessed July 11, 2020.

14. Jacobs PD, Hill SC, Abdus S. Adults are more likely to become eligible for Medicaid during future recessions if their state expanded Medicaid. Health Aff. 2017;36(1):32-39. https://doi.org/10.1377/hlthaff.2016. 1076
15. Decker SL, Lipton BJ. Do Medicaid benefit expansions have teeth? The effect of Medicaid adult dental coverage on the use of dental services and oral health. J Health Econ. 2015;44:212-225. https://doi.org/10.1016/j. jhealeco.2015.08.009.

16. McNichol E. Out of Balance: Cuts in Services Have Been States' Primary Response to Budget Gaps, Harming the Nation's Economy; 2012. https://www.cbpp.org/research/out-of-balance.

17. Lipton BJ, Decker SL. The effect of health insurance coverage on medical care utilization and health outcomes: Evidence from Medicaid adult vision benefits. J Health Econ. 2015;44:320-332. https://doi.org/ 10.1016/j.jhealeco.2015.10.006

18. Tax Policy Center. Federal Receipt and Outlay Summary 1940 to 2025. https://www.taxpolicycenter.org/statistics/federal-receipt-and-outlaysummary. Published 2020. Accessed April 24, 2020.

19. Centers for Medicare and Medicaid Services. Families First Coronavirus Response Act - Increased FMAP FAQs. https://www.medicaid.gov/stateresource-center/downloads/covid-19-section-6008-faqs.pdf. Published 2020. Accessed April 24, 2020.

20. Mann TE, Ornstein NJ. It's even worse than it looks: how the American political system collided with the new politics of extremism. New York: Basic Books; 2016.

21. Mann C, Dervan E. Ensuring People Have the Medicaid Coverage They Need During the Economic Crisis; 2020. https://www. commonwealthfund.org/blog/2020/ensuring-people-have-medicaid-coverage-they-need-during-economic-crisis. Accessed July 11, 2020.

22. House Resolution 6379; 2020:241-250. https://www.congress.gov/116/ bills/hr6379/BILLS-116hr6379ih.pdf. Accessed July 11, 2020.

Publisher's Note Springer Nature remains neutral with regard to jurisdictional claims in published maps and institutional affiliations. 